\title{
Integrating modes of policy analysis and strategic management practice: requisite elements and dilemmas ${ }^{\wedge}$
}

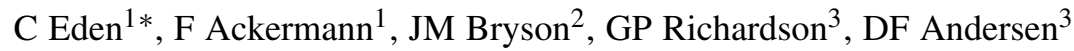 \\ and CB Finn ${ }^{4}$ \\ ${ }^{1}$ University of Strathclyde, Glasgow, Scotland, UK; ${ }^{2}$ University of Minnesota, Minneapolis, MN, USA; \\ ${ }^{3}$ University of Albany, State University of New York, USA; and ${ }^{4}$ College of Saint Rose, Albany, NY, USA
}

There is a need to bring methods to bear on public problems that are inclusive, analytic, and quick. This paper describes the efforts of three pairs of academics working from three different though complementary theoretical foundations and intervention backgrounds (ie ways of working) who set out together to meet this challenge. Each of the three pairs had conducted dozens of interventions that had been regarded as successful or very successful by the client groups in dealing with complex policy and strategic problems. One approach focused on leadership issues and stakeholders, another on negotiating competitive strategic intent with attention to stakeholder responses, and the third on analysis of feedback ramifications in developing policies. This paper describes the 10-year longitudinal research project designed to address the above challenge. The important outcomes are reported: the requisite elements of a general integrated approach and the enduring puzzles and tensions that arose from seeking to design a wide-ranging multi-method approach.

Journal of the Operational Research Society (2008) 00, 1-12. doi:10.1057/palgrave.jors.2602575

\section{Introduction}

As the complexity of public problems and the speed with which they arise increase, it becomes important to develop more effective methods designed to help address these problems. The challenge is to bring methods to bear on public problems that are inclusive, analytic, and quick (Peters and Pierre, 2003). The methods need to be inclusive in terms of the content knowledge, stakeholder interests, and skill areas brought to bear on the problem. The methods should be suitably analytic, so that the wrong problem is not solved, solutions do not actually create the problem that was to be solved, or worse problems result (Mitroff and Featheringham, 1974; Wildavsky, 1979). Finally, the methods should be quick, so that they can be used by busy managers, and ensure problems do not fester or become worse while solutions are being developed. In practical terms, this means combining the best of several well-established and successful approaches.

The challenge is made more difficult because, while it is not necessarily hard to cope with any two of these challenges, it is extremely hard to cope effectively with all three

\footnotetext{
*Correspondence: C Eden, Strathclyde Business School, 199 Cathedral Street, Glasgow G4 OQU, UK

E-mail: colin@gsb.strath.ac.uk

$\sqrt{5}$ Earlier versions of this paper were presented at the Group Decision and Negotiation Conference, Karlsruhe, Germany, 25-26 June 2006; the Third Sino-American Conference on Public Administration, Beijing, P. R. China, 8-9 June, 2006; and the Tenth Annual Conference of the International Public Management Association, Glasgow, Scotland, 10-12 April, 2006.
}

simultaneously. In other words, it is possible to engage a fairly large group of people and multiple stakeholders in a quick strategic planning process, but without much exploratory and in-depth analysis (Holman and Devane, 1999). It is also fairly easy to engage a large group of people and to include significant amounts of analysis, but doing so quickly is hard. Finally, it is relatively easy to do quick analysis, but only with small groups working on relatively straight-forward problems (Behn and Vaupel, 1982).

Among academics there are few who have substantial experience of working with groups on such problems and with the objectives set out above. This paper describes the efforts of three pairs of academics working from three different though complementary theoretical foundations and intervention backgrounds (ie ways of working) who set out together to meet this challenge. Each of the three pairs had conducted dozens of interventions that had been regarded as successful or very successful by the client groups. All had considerable experience working with teams of managers in both the public and private sectors who were struggling with complex policy and strategic problems. Each pair was convinced that their own approach could be improved by including the 'missing elements' which were embedded in the other two approaches. One approach focused special attention on leadership issues and stakeholders, another on negotiating competitive strategic intent with particular attention to stakeholder responses, and the third on analysis of feedback ramifications in developing policies. 
The intention was to develop an approach to integrating modes of systems thinking into public policy making and strategic management practice. Beyond the challenges identified above, the common purposes were: (a) to enable groups to come up with good ideas worth implementing, that can be implemented, and are likely to have the coalition of support necessary for implementation and (b) to ensure that what gets decided by a client group as a result of our facilitation has the group's highest confidence that the policy or strategy will be robust and effective over the long term (ie that it is going to work out over time).

This paper describes how seeking to meet these aims entailed a longitudinal developmental research process over 10 years which led to: establishing the requisite elements of a general integrated approach and the discovery of enduring puzzles and tensions that arise from seeking to design a wide-ranging, multi-method approach to addressing complex problems. Consequently, the paper makes a contribution to the field by: (a) developing an integrated range of research methods for exploring the relationship between theory and practice in multi-method work; (b) suggesting an approach to integrating modes of systems thinking into policy making and strategic management that is more inclusive, analytic and perhaps quicker than others; (c) identifying what appear to be the key aspects of any successful multi-method approach; and (d) suggesting the puzzles and dilemmas that must be acknowledged by those wishing to employ more wide ranging multi-method approaches to helping policy makers. In addition, the paper concludes by summarizing the lessons we as a group have learned from working to understand and integrate our different approaches.

\section{The story in brief}

In 1995 we gathered as a group of six scholars to discuss and synthesize over a century of combined experience in the theory and practice of strategic planning (from two complementary points of view) and policy making using system dynamics modelling. We also had a number of initial reasons for believing that time devoted to cross-disciplinary theory building would be useful. For example, all schools of thought present shared a common practice of building different types of word-and-arrow diagrams, often with live-screen, computer-projected support, in front of client groups who were struggling with important strategy and policy problems. We felt that this was more than coincidental and that we might share some deeper theoretical underpinnings.

We discovered through extended dialogue however, that we had deeper reasons to be talking to one another. As it turns out, system dynamics modelling has implicit in its core an implied theory of policy and strategy development (Milling, 1989; Zahn and Greschner, 1993). And strategic management is in the end focused on the dynamics of changing a system (eg Morecroft, 1984; Warren, 2002). In many ways and for many years we believed we had been looking at the opposite sides of the same coin.

The group continued to meet, talk, think, and sketch for a number of years. We met twice a year for a total of 2 weeks each year. At the end of this time, we wound up with three conceptual maps that laid out for us our thinking. These conceptual maps sought to show the interrelationship between both theoretical assertions and their practical implications. The first part of the paper discusses the research design. The remaining parts of the paper recount the next stages of research: integrating the approaches, identifying requisite elements of any approach seeking to address the above needs, and finally discussing some remaining, but important dilemmas and puzzles.

\section{Research design}

The stages in the research were as follows:

Stage 1: The first stage involved mapping the assumptions and theories that guided ways of working. Commonalities and contrasts were explored. Assumptions and theories were merged where possible. This first stage involved extensive conversations facilitated by the use of a range of recording techniques.

Stage 2: The second stage focused on the design of a 'new approach' that encompassed, to the greatest extent possible, all of those concepts important to each researcher. The research strategy for producing the design was to develop a teaching programme to transfer the new approach to 'nai ve' enthusiasts. Developing the teaching programme therefore forced detailed explication of abstract concepts, and so induced greater understanding and clarity about how to explain and present the assumptions and theories in practice.

Stage 3: The next stage entailed detailed logging of the teaching experiences (three occasions: two in the US and one in the UK). This process enabled us to attend to difficulties of understanding and explication experienced by the researchers, and also to focus on the difficulties of understanding and application by the 'students'. This stage was designed to test our ability to present the combined approach to others and so encourage elaboration and questioning of the coherence and consistency of the merged concepts, theories, and assumptions.

Stage 4: The fourth stage involved incorporation by the researchers of different aspects of the new thinking into their academic writing and practice. As a result, the three approaches with which the process began all changed somewhat, and in some cases changed substantially.

Stage 5: The final stage featured designed reflections on why some aspects of the new approach were enthusiastically received while others were rejected by different members of the group. These reflections resulted in the identification of commonalities (where all agreed on an aspect) and puzzles and dilemmas (where there were differences of opinion) presented later in the paper. 
So to summarize, Stages One and Two of the research concentrated on developing a conceptual framework (represented by the densely concentrated conceptual maps). The framework was debated extensively, examined against the theory supporting the different approaches and tested through constant reference to organizational experiences. The researchers were mindful of the potential dangers of 'mixing methods' where disparate and conflicting theories are brought together (Eden, 1990), as well as the potential benefits and conceptual concerns that might ensue (Mingers and Brocklesby, 1997; Munro and Mingers, 2002). Moreover, throughout the development process considerable personal learning was encouraged and occurred. Learning occurred about both the theory and practical application of the different approaches (not just by those listening to the proponents, but by the proponents themselves as they were forced to articulate and justify their positions). This further helped to provide a sense that the emergent framework was robust.

The second, third and fourth stages took a more action research stance (Eden and Huxham, 1996; Blenkin and Kelly, 2001). Insights were immediately gained during the Stage 2 process of designing a fit medium for teaching the framework (eg the demands being made on students). Further insights were revealed during Stage 3, the teaching of the actual class itself. For Stage 3, the first class of 'students' involved all of the authors and a range of policy and strategy masters students along with some practitioners. The researchers/teachers then took time after the class to reflect on the process by following a cyclical process of learning that is central to action research and action learning (Argyris and Schon, 1978; Kolb, 1984; Checkland and Holwell, 1998). As a result, adaptations were made to both the syllabus and framework. The group then taught the class a further two times, once in Minneapolis and then in Glasgow. Following these experiences, in Stage 4, the conceptual framework was also put to the test in various consultancy/research situations facilitated by one or more of the authors (eg see Howick et al, 2006). Learning from these cases was informed by the process guidelines set out by Eisenhardt (1989).

Throughout these applications notes were taken before (particularly in the case of the consultancy projects, eg detailing the objectives, general steps in the process, stakeholder involvements, etc), occasionally during (recognizing the difficulties of facilitating and reflecting), and after each intervention. The team then began to reflect in Stage 5 on what they had learned, and what this meant for the framework. Not surprisingly, a number of common interests surfaced (some of which had been identified early in the development of the framework), along with a range of tensions or dilemmas.

\section{Distilling an approach to strategy making and policy analysis}

The purpose of this paper is to report on the more generic issues that arose from seeking to develop such an integrated approach. (Readers interested in knowing more about the details of the integrated approach are referred to Andersen et al, 2006.) However, in brief, there are four dominant 'process modules' that are linked in the approach, each of which is linked to one of pairs of authors. The modules are: (a) stakeholder mapping, (b) strategy mapping, (c) developing a 'livelihood scheme' or 'business model', and (d) feedback system simulation and modelling. Although there is a typical cycle of use for the process modules, it is unlikely that the ordering is the same in every instance. As the approach is used, contingencies determine the stage at which final agreements are made by the client group, as well as any need for additional cycling around the four different process modules. Nevertheless, each module is bounded by a particular approach to modelling, and the modelling has specific purposes and formalities that make sense within the module's context.

The role of leadership provides the 'surround' to the whole approach-it influences the way in which each of the 'process modules' offered by each of the author pairs is undertaken, and the manner in which connections between them are made. The contingent use of the four process modules are guided by the essential aspects of good leadership. Leadership in, and for, this approach has somewhat different implications from those that dominate the leadership literature. Within the context of group modelling, acknowledging and treating as valid multiple perspectives deriving from multiple expertise and multiple values is regarded as crucial. Recognizing the need to reach negotiated agreements that sustain strong and trusting working and personal relationships is taken to be a fundamental aspect of sound leadership and so influences the design and facilitation of group sessions. To this end leadership will require the employment of forums for discussion, arenas for making and implementing decisions, and formal and informal courts for managing residual disputes and enforcing underlying norms in the system (Bryson, 2004). The implication of this approach to leadership is that supporting, sponsoring and championing these type of social processes and the design and use of these kinds of settings are central activities.

Typically, the approach starts with the first process module focused on understanding stakeholders. This is because a key part of designing an intervention is determining who should be involved-for procedural justice as well as procedural rationality (Ackermann et al, 2005a,b). Participants are typically at least some of the key stakeholders-those who can have a significant impact over the success or otherwise of the strategy - and it is an important component of leadership to ensure those involved can actively participate. However, this process module also includes the identification of others who might need to be consulted or whose views must be taken into account (Finn, 1996; Bryson et al, 2002; Bryson, 2004). The formalities of the modelling process here focus on stakeholder interactions and relationships-and especially the extent of overlapping perspectives and values. Each of 
the key stakeholders will have their own perspective on the important issues to be addressed and the way in which they interact. The outcome of the process is a clear understanding not only of who has to be involved in the next stage but also in what form.

The second process module encourages the participants to express their own views about these issues and to share them with others as part of a strategy mapping process. The client group expect to gain an understanding of the breadth of issues, how they interact, and how they cluster into major issue themes. The process may need to involve role playing the other stakeholders in mapping their views. The maps of issue interrelationships lead to a model that reflects a particular nature of causality: where issues imply emergent goals, and issues are derived from a variety of triggers or causes. The map shows a hierarchy where problems (or opportunities) cause issues which suggest goals or aspirations Huff and Jenkins, 2001). The map is amenable to analysis to help understand the structure of an often complex network of issues, and the analysis depends upon the use of formalities in the mapping process (Bryson et al, 2004). The mapping process is undertaken with the group using visual interactive modelling (VIM) tools (such as the 'oval mapping technique' (Bryson and Finn, 1995 (Eden and Ackermann, 1998 \#2990) (Eden and Ackermann, 2001a,b \#5120)) or special purpose software). The outcome of this module is agreements about the relative priority of issues and a draft of the goals that will drive policy considerations.

The third process model-developing a 'livelihood scheme' or 'business model'-recognizes that the ability to deliver the goals and resolve the priority issues depends upon understanding the competences of the organization and its stakeholders. In the 'for-profit-sector' this is explored by developing, understanding and exploiting the 'business model'. However, in the 'not-for-profit sector' the notion of a business model is discomforting and can be misleading. For the not-for-profit sector the term 'livelihood scheme' is more appropriate (Eden and Ackermann, 1998) and recognizes that the delivery of goals demands understanding the core competences (and preferably core distinctive competences) that can enable the delivery of a mandate (the 'given goals'). This process module helps the client group explore their ability - through competences - to deliver the goals, and so develop the strategies to resolve issues and create a sustainable strategic future, where the success, at least, will depend upon the exploitation and protection of the core competences (Ackermann et al, 2005a,b). The process seeks to construct a map of the competences and their role in delivering goals (extending the problems/issues/goals hierarchy).

Client groups have experiences that suggest there are often unexpected and unintended consequences from apparently well thought-out strategies and possible policies. For the client group the fourth process module is focused on testing the draft policies and strategies by exploring their ramifications over time through use of system dynamics modelling. In addition, exploring the business model often reveals core distinctive competences that have beneficial reinforcing tendencies, directly implying a feedback system, but one that when interacting with the environment may fail to work as expected (Andersen and Richardson, 1980). The 'best' policies are discovered through the use of a feedback systems simulation model to test draft policies and strategies. The strategies designed to sustain competitive advantage through the strategic protection of core distinctive competences will also be tested.

The process module explicitly focuses on acknowledging that the ramifications of policy implementation are complex and can produce unintended consequences (Richardson, 1991). Thus, the modelling seeks to understand how, over time, the intended, rational, goal-seeking actions of one group of actors may be compensated for by the contrary actions of other stakeholders or actors, or by the 'natural' environment. The modelling explores how compensating feedback structures can produce observed patterns of policy resistance. This process module brings a sense of dynamics to the strategy discussion. The formalities of the causal modelling now focus on the need to simulate the future through tracking the impact of feedback dynamics. As with all the other modules, the modelling is undertaken with the group and, in this case, uses visual interactive system dynamics simulation software that is transparent to the client group.

As a result of the feedback system simulation modelling effort, the 'best' policies emerge. However, these have been developed without full attention to how different stakeholders, both within and outside of the organization, will react. The second use of the stakeholder process module helps ensure that the strategy or policy is as robust as it can be.

\section{Requisite elements in the context of application}

The reflection process in Stage 5 of the research revealed a number of common interests or themes across our joint and individual work. The themes are interrelated and include: leadership, the management of meaning, the use of VIM, the development of a holistic view of the problematic situation, and issues relating to facilitation. We assert that these themes represent requisite elements of any integrated multi-method approach to dealing with complex policy making and strategic management problems. Each of these themes is explored in more detail below with particular emphasis given to their implications for practice.

\section{Appreciating the role of leadership}

Unlike the other themes, the leadership theme was less understood, particularly in relation to its significance for practice, at the beginning of the discussions. Little attention had been given to understanding what leadership comprised in the context of policy making and strategy formulation and implementation and how it could positively impact practice. 
We came to understand the significance of leadership as the inspiration and mobilization of others to undertake reasoned collective action (see Crosby and Bryson, 2005), and therefore as different from management. In particular, more inclusive forms of input and decision making were seen as an important means to optimize outcomes. As this aspect was developed, it became clear that a highly significant aspect of good leadership involved acknowledging, and treating as valid, the expression of potentially controversial views, so that perspectives could be considered on their merits rather than just because of who proposed them.

Each of us relied on a variety of methods and tools to elicit ideas from all group members. One such method included the use of a group support system (GSS) that allowed direct entry of views to a publicly displayed 'picture of issues' (see section below on visual interactive models). GSS's enable participants to surface material anonymously, which helps open up and stimulate contributions and ensures wider perspectives are considered (Ackermann and Eden, 2001). In addition, every member of the group had developed a variety of methods to allow for more inclusivity. For example, the use of post-its (or 'ovals'-oval-shaped cards) to capture material was a 'manual' method for increasing the integration of multiple perspectives (for more on oval mapping, see Eden and Ackermann, 1998; Bryson et al, 2004). Each of these processes ensures procedural justice (Kim and Mauborgne, 1995), another aspect of leadership.

Another important contribution to the development of the approach derived from the need to pay attention to multiple leadership roles during the process; for example, the need for sponsors, champions, facilitators, and the creation of teams (Bryson, 2004). Paying attention to who the sponsors of the process attends to the need to 'manage up' the organizational hierarchy, which helps ensure the political feasibility of any agreements made (both in terms of providing financial support as well as political support).

\section{The role of managing meaning}

As our teaching and attempts to use a more integrated approach in practice unfolded, the significance of the management of meaning emerged. Each of us believed in the importance of attending to the role of group support in facilitating the management of meaning when it came to improving his or her practice. Indeed, as discussions unfolded over the years, we increasingly understood how important it was for those in facilitated processes to accept that the shifting of meanings is a crucial aspect of reaching a negotiated settlement (Pettigrew, 1977). Aspects of the meaning management process include the idea that at times language needs to be deliberately opaque, and that what is meant by a particular statement to one person will be interpreted differently by another.

We came to see that a particularly helpful way of negotiating new meanings was through having the client group develop and change some form of word-and-arrow diagram. For one thing, word-and-arrow diagrams can be used to structure the different perspectives raised by members of a planning or policy-making group. Each of us had experienced the power of his or her versions of word-and-arrow diagramming to structure and help groups manage complex, messy situations. In particular, the structuring process and resultant structure of argumentation helps groups manage the complexity rather than simplistically reduce it.

In the case of causal mapping (Causal mapping is one of the forms of word-and-arrow diagram.) (Bryson and Finn, 1995; Eden and Ackermann, 1998) participants begin to explore their linked perspectives. New material can be surfaced that elaborates and expands the different causal chains to illustrate the different points of view, thus building a sense of shared understanding. Dilemmas thus can be identified, and possible contradictions displayed, discussed and resolved. Causal maps (see Bryson et al, 2004) enable the group to move from individual meanings to a meaning increasingly shared by the group. The group is able to build a model encapsulating robust causal thinking to enable agreement on mission, goals, strategies, and actions. In the case of word-and-arrow diagrams that help construct simulation models (causal loop diagrams; see Richardson and Pugh, 1981; Wolstenholme and Coyle, 1983; Sterman, 2000), the perspectives often link back to form closed causal loops, revealing the feedback nature of the 'real world' (Richardson, 1991). The appreciation of these several different approaches to word-and-arrow diagrams influenced our practice through recognition of the importance and richness of qualitative word-and-arrow diagrams, and also the rigour of quantifiable word-and-arrow diagrams. The practical implication for the group was the need to acknowledge strategic policy and planning processes are enriched by achieving a suitable balance between equivocality (and thus meaning management) and the precision required for policy analysis. The focus on the balance of equivocality and precision accentuated the appreciation of the political nature of group decision making, and that meaning is typically contested. Achieving political feasibility is an important key to policy making in practice, which means meaning management and policy analysis must be effectively joined (Eden and Ackermann, 1998).

\section{The role of holism}

Each of the three original ways of approaching strategic and policy intervention recognizes some form of holism in the extent and nature of the analysis. All of the authors explicitly sought to widen their scope and develop a more holistic view. In each of our cases, holism was seen as being achieved through gaining a picture of the whole and its emergent properties rather than focusing on discrete parts.

The different approaches to holism addressed issues of analysis through attention to: collecting and identifying the emergent properties of multiple perspectives (Eden and 
Ackermann, 2001a,b), involving appropriate stakeholders (Bryson, 2004), analysing and seeking to manage external stakeholders (Finn, 1997; Eden and Ackermann, 1998; Bryson et al, 2002), and exploring and intervening in feedback in social systems (Richardson, 1991; Andersen et al, 1997). By building an approach that was more holistic the authors expected to encourage originality, synthesis of issues and ideas, and the practicality and long-term effectiveness of strategy and policy interventions.

When multiple perspectives are collected through the development of a group causal map, patterns emerge through analysis of the structure and content. These patterns typically are: clusters, central threads of causality, emergent counter-intuitive loops, etc. Each of these patterns indicates policy foci, problematic issues, constraints and possible self-sustaining feedback.

Managing strategic change involves having good ideas worth implementing and the coalition of support necessary to adopt the changes and to protect them during implementation. Coming up with good ideas and the necessary coalition of support typically are connected, since people are likely to feel more ownership of, and commitment to, ideas they helped develop. Careful stakeholder analyses can help inform decisions about whom to involve, in what ways, when, and for what reasons. Stakeholder analysis is fairly well developed in the strategic management literature.

However, these analysis methods typically do not illuminate who all the stakeholders might be in complex, feedbackrich systems. There is thus a need to discover and include (at least in the analysis) 'derivative' stakeholders (Phillips, 2003). Discovering who they are and taking their interests into account can increase the likelihood of a successful outcome (as noted earlier in the discussion regarding the necessity of a coalition of support). The benefit of discovering derivative stakeholders is not well developed in the system dynamics literature; nonetheless, system dynamics analysis can help reveal who these other stakeholders might be and what effects policy changes might have on them (Phillips, 2003).

The internal and external world of stakeholders is explored through a stakeholder analysis that pays attention to their power to support or sabotage efforts and the nature of their interest in so doing. Stakeholders are seen as having the ability potentially to make or break particular strategic options and so the task is to know how to intervene to shift the use of power or change the interests of stakeholders should the need arise.

Exploring and intervening in feedback systems is a specific aspect of taking a holistic view. Taking a feedback perspective can reveal the natural circularities that exist in complex systems. Perceiving circular causality is crucial for understanding the endogenous forces that contribute to the ways a system changes over time. For example, goal-seeking feedback structures are present in every purposeful decision or policy: conditions are perceived, compared to goals, and actions taken to close the gaps between desired and actual. In contrast to such goal-seeking loops, other feedback processes tend to be self-reinforcing, generating instabilities, goal-divergent behaviour, and growth or decline.

A feedback perspective, focusing on these two kinds of processes and facilitated by word-and-arrow maps is a powerful tool for revealing sources of policy resistance in complex systems. Multiple agents can create a system in which the intended, rational, goal-seeking actions of one group of actors are compensated for by the contrary actions of other actors, or by the 'natural' environment. Compensating feedback structures can produce observed patterns of policy resistance, such as 'worse-before-better' behaviour, 'fixes that fail,' and the 'tragedy of the commons' (see, eg Forrester, 1969; Senge, 1992; Pettigrew et al, 2003). Using word-and-arrow maps to reveal circular causal processes and feedback loops thus helps to foster client understanding of potential sources of systemic resistance that could defeat clients' preferred policies.

While some insights of this sort are achievable with qualitative maps alone, accuracy and confidence in the dynamic implications of these causal views is dramatically enhanced by quantifying them in formal simulation models and playing them out over simulated time. Developing robust and flexible models helps client groups understand the connections between system structure and behaviour over time and explore with growing confidence the dynamics of policies in different scenarios.

\section{Facilitation}

In the introduction we argued that methods for effectively addressing public problems should be inclusive, analytic and quick. In terms of facilitation, the most significant interest of the authors in facilitation was in doing something fast and inclusive with a group. As the authors worked together there was an increasing appreciation of their different means of making progress. Each author believes that in order to make fast tangible progress facilitators need to create milestones against which to assess progress in order to provide a powerful incentive to the group to keep working. Each also believes that this need for 'quickness' must be tempered with the need to ensure that the group appreciates what is being sought by the facilitator and how the process is unfolding, and also feels some sense of control over the process rather than feeling overwhelmed.

All authors take for granted that facilitation is a key skill and that it is hard to teach and to learn. This is partly because a good facilitator requires a combination of skills and the ability to execute several roles (Andersen and Richardson, 1997). Facilitation demands soft skills (such as how to deal with people, personalities, power, etc), modelling skills (ensuring formalisms are attended to), and also technology skills (where computer models are being built). Each of these informs and is informed by the others. Over the course of an intervention, the balance shifts between these requirements, 
sometimes requiring more process attention, at other times more content management.

For all of the authors of this paper a 'taken for granted' aspect of facilitation was the use of VIM tools. These were different, but similar, in each case. VIM involves reaching agreements with people rather than working in the 'backroom', thus attending to the call for inclusivity, analysis and speed. The model enables all perspectives to be continually captured, reviewed and amended. This continual process of subtly allowing participants to change their minds and move from a range of divergent opinions to a shared outcome helps reach a negotiated conclusion.

Visual interactive models are designed to create a dialectic_-a way of providing a structure against which participants can explore their understanding of the situation, try out different options, and consider the political climate. Dialectic models are also a way to combat the harmful effects of single-loop learning and at the same time to promote the power of double-loop learning from an individual and group perspective (Argyris and Schon, 1974). There is a tension in this dialectic, best revealed in the work of Zagonel (Zagonel, 2002, 2003, 2004), between mapping and modelling the 'real world' (building microworlds) and mapping and modeling shared mental models (building consensus). The two are not necessarily contradictory, but they create different emphases and involve somewhat different intervention strategies. Facilitators need to be adept in managing the resultant tension effectively.

\section{Dilemmas and puzzles in integrating modes of policy analysis and strategic management practice}

While there were a number of common themes, we also found that we confronted a number of dilemmas or puzzles as a result of attempting to integrate three different approaches into the new conceptual framework. These dilemmas or puzzles are areas of tension, if not actual incompatibility, among the approaches; and it is not clear if or how the tensions can be resolved. They are tensions that span both the theoretic underpinnings of the approaches as well as the practice. Some of them are not specific to the integrated framework, but generic to all attempts at mixing methods (eg the demands placed on managers and policy makers). Perhaps managing the tensions in practice, and not in theory, is the best that can be done.

The following tensions are discussed: getting the 'right policy' versus reaching agreement; strategic management versus strategy or policy analysis; which process steps to follow; the extreme demands on managers or policy-makers and on facilitators and analysts; and, can conflicting theories be practical together?

\section{Getting the 'right policy' versus reaching agreement}

Most probably would agree that policy makers should expect, value, and receive sound policy analysis and not just agree to act when a group has reached agreement. Most probably would also agree, at least in the abstract, that public policy makers' responsibility to the public ought to be paramount and that effective policies and strategies cannot and should not emerge from the simple fact that a group has reached apparent agreement to move forward. These views are compatible with the authors' recognition that the world, both socio-political and physical, obeys 'rules' (seen as regularized patterns of behaviour) and that sound policy must take these rules into account. Unless these rules are explored with respect to policy proposals, then a policy-making group may make policy that has unintended, surprising, and negative consequences.

Nevertheless, there is a tension between this recognition and the authors' approach to policy analysis. The authors are not from the usual policy analysis school (eg Bardach, 2004; Weimar and Vining, 2004), but rather have a commitment to working directly with policy makers rather than through 'back-room' analysis. Thus, there is a comfortable commitment from all towards ensuring that policy is created by those who will act to implement, and so the need for high levels of ownership. Achieving ownership, however, in some circumstances may come at the expense of good policy.

As we said earlier, our agreed objective is to come up with good ideas worth implementing, that can be implemented, and to have the needed coalition of support necessary for implementation. And yet, we also stated our aims include ensuring that what gets decided by a client group as a result of our facilitation has the group's highest confidence that it is going to work out well over time. As these aims were explored and discussed it became increasingly obvious that their meaning, as exemplified by practice, represented elements of tension. The tensions involve the emphases within each of these aim statements: 'good ideas' versus 'coalition of support,' and 'going to work out over time' versus 'group's highest confidence,' where the group's confidence may be highest in what they intuitively believe, rather than with what good analysis shows. Needless to say, these are not absolute dichotomies. For example, confidence will come from analysis of good-ness as well as from the social outcomes that lead to emotional commitment that risks 'group-think' (Janis, 1972). Through using the analysis embedded within the new, integrated approach, the dangers of 'best fit' (Schweiger et al, 1989; Camerer and Johnson, 1991) can, to some extent, be avoided. Nevertheless, the 'tension' is important in practice.

Another aspect of the tensions is that, on the one hand, equivocality is seen as crucial to promoting and facilitating negotiated agreements. This is achieved through providing a working environment for the group which encourages sharing of views and appreciating and respecting multiple perspectives. As a result, development of shared understanding and meaning unfolds. In the case of equivocality, there is less concern about the 'right' policy or a 'good' policy-however, there is an acute awareness of the dangers of group-think, and thus of the need to attend to multiple perspectives. Precision, on the other hand, aims to move things forward through 
hard and deep thinking, permits complexities to be further explored, and assesses values and meaning.

In practice, this 'tension' is illustrated by the different ways of using one of the enthusiasms of all of the authors-formal word-and-arrow diagrams. Good policy analysis of implications over time is guided by the use of a causal loop diagram that can be tied to a formal simulation model (Vensim (Vensim is System Dynamics simulation software that can be used directly with the decision-making group as a form of Group Decision Support System (GDSS)—see www.vensim.com.)), whereas negotiation through the representation of multiple perspectives and views comes through a (Decision Explorer (Decision Explorer is a cause mapping software that is used as a GDSS, and enables an extensive range of analyses of the map-see www.banxia.com.)) cause map. Cause maps take as some sort of fundamental presumption that there are both shared and conflictual cognitions among a group of individual managers. Agreements follow from sharing and negotiating the integration of these views. The subjective group map is expected to reflect a belief that managers do not exist in delusional realities, and so these maps will routinely point to measurable and inter-subjectively verifiable objects. Reality is defined through the combined richness of multiple perspectives, but whether that 'reality' actually reflects some 'independent' reality is an open question.

On the other hand, at its base, a dominant view of a system dynamics (Vensim) map and simulation model is that strategic realities involve a feedback mechanism that exists somehow apart from mental maps of managers. These feedback mechanisms can have an existence more or less separate from the messy business of how divergent stakeholders think about that reality. In fact, one of the purposes of well-done models (which can be seen as 'micro-worlds') is that they can help to correct deficiencies in managerial 'mental models'. In other words, the presumption of this view is that the model is somehow correct and policy makers' mental models are messed up and need to be corrected and aligned, and that an iterative process of mapping, modelling, simulating, and reflecting can help move the group toward a shared model that is more 'correct'.

All of the authors accept both premises, up to a point, but in the end the collision occurs through the tension of the social construction of reality (Berger and Luckmann, 1966) as against a driving need to model the 'real' world. So, even though every author wanted to merge theory, method and practice, our academicltheoretical work (rooted in the alternative theories about the nature of the social world), as expressed through the practice of working with groups, made it more difficult than expected. Nevertheless, a few attempts have been made. Ackermann and Eden have implemented a combined approach for the purposes of supporting litigation (Ackermann et al, 1997; Howick et al, 2007). However, they have done so by supposing that the subjectively expressed cause maps of witnesses are statements of fact that then get reflected in a system dynamics simulation model, and that the outcome of the model will be used to correct the witnesses' assertions about facts. There is also a recent example of using cause maps to inform and influence system dynamics simulation modeling in the context of policy analysis (Howick et al, 2006).

Nevertheless, we continue to assert that good ideas are not enough. There must also be a coalition large enough and powerful enough to adopt the ideas and protect them during implementation. Said differently, good ideas by themselves are pretty useless-little better than a typical New Year's resolution; but strong coalitions organized around bad ideas are really bad. Good ideas and supportive coalitions are required to advance the common good. Thus we recognize that there is more to do in order to combine fully each modeling perspective with comfort, commitment, or confidence.

\section{Strategic management versus strategy or policy analysis}

As we became more engaged in seeking to merge approaches it gradually became clear that in public management there are probably two different emphases reflected in the authors' ways of working. In summary, these may be seen as: (1) leading and managing strategic change and developing a portfolio of strategic programs to manage change and (2) testing out the viability of alternative policies with respect to a particular major strategic issue.

The first of these aims supports a group in the development of an all-encompassing strategy for the organization: the subject of Strategic Planning for Public and Nonprofit Organizations (Bryson, 2004), and Making Strategy (Eden and Ackermann, 1998; Ackermann et al, 2005a,b). In the context of developing strategy, the second of these aims, to undertake policy analysis especially through an exploration of feedback systems, seems appropriate. This is because we recognize that many strategies fail because decision makers do not recognize the dynamic ramifications of the policies' imposition, for example, through not understanding the presence of simple vicious cycle archetypes (Senge, 1992).

And yet, as overall strategic planning takes place in practice, the number of strategies that are developed and the complex relationships between them overwhelm the possibility of exploring them through the construction of simulation models. Similarly, the need to recognize multiple organizational goals and a hierarchy of strategies to goals, distinctive competences to goals, strategic programme to support strategies, and most importantly ownership of strategies and consistent committed leadership to deliver them is apparent to all of the authors. Unfortunately, as modelling to test alternative policies proceeds, attention becomes inevitably focused on the behaviour of the 'external' world of policy impact explicitly highlighting possible divisive or unintended effects of a prior strategic agreement. This focus can detract from the commitment and will to deliver policies within the wider context of organizational strategy; in other words, the analysis can undermine political feasibility. 


\section{Process steps}

In their publications, the authors suggest following approaches to strategic management and policy analysis that are in some ways broadly similar, but also contain major differences in detail (Andersen and Richardson, 1997; Eden and Ackermann, 1998; Bryson, 2004). Beyond that, the authors agree that any application of their processes in practice should be tailored to the situation at hand. These differences suggest limits to the integration of the separate approaches.

For pedagogical purposes, the authors did articulate a generic strategic management process and use it to organize instruction in the integrated approach. The process provided a systematic way of understanding the key concepts and ways of thinking about managing strategic change embodied in the integrated approach, and of developing specific skills related to tools and leadership tasks. We have been quite successful in teaching the integrated approach and of incorporating aspects of it into the other courses we teach (Andersen et al, 2006).

But the need to teach the approach may have forced us to submerge differences in the theoretical underpinnings of our separate approaches, rather than to fully articulate and integrate them. Complete integration at a theoretical level remains elusive-not least because of the time-consuming nature of the task and our separate geographic locations. In addition, there is little sound empirical work detailing exactly what to do, how, where, when, why, and with whom in order to effectively manage any strategy change process, let alone our own. Further, there is little sound empirical work on how to think in detail about the situations in which strategy change processes might be pursued and to which they might be tailored. So we face the task of integrating our separate approaches and then the task of figuring out how to adapt the approach to differing circumstances. How to undertake-let alone accomplish—each task represents a major puzzle.

\section{Extreme demands on managers or policy-makers and demands on facilitators and analysts}

Although it was apparent that each approach provides added value in terms of increased richness and robustness, it became increasingly clear that each approach, in its own right, makes huge demands on both facilitators and participants. Needless to say, the demands of any good facilitation requires both content management skills as well as process management skills (Eden, 1990; Huxham and Cropper, 1994; Andersen and Richardson, 1997), let alone adding the requirement for alternative modelling skills that are also at least theoretically misaligned in the manner discussed above.

To truly integrate the methods, a detailed knowledge of all the approaches is necessary. Is this demand simply too difficult for even the best analyst-facilitators? Certainly, there are few, if any, that can traverse the breadth of skill in method and facilitation, although there are many who may do this as long as the analysis can be done in the 'back-room'. Facilitating 'on-the-hoof' with an interactive model is known to be difficult (Ackermann and Eden, 1994; Andersen et al, 1997) but to add the need to straddle the ability to model nuance and richness as well as ascertain effective formulas for variables in a simulation model adds to the burden. The participants are also expected to traverse different visual representations, pay attention to leadership demands, and, not least, address the mental demands of working with complex strategy making or policy problems. Addressing the richness of multiple perspectives developed using Decision Explorer cause maps (often containing 800-1000 or more statements) can be debilitating for some participants in a workshop (Eden et al, 1981). To then expect participants to turn their attention to system dynamics influence diagrams forces both facilitators and participants to move from one syntax to another-but it is more than just syntax, it is different ways of thinking and perceiving.

To repeat, the major challenge is to be inclusive in terms of people and perspectives, suitably analytic, and quick. The combination of all of the approaches is inevitably targeted at situations that are complicated in themselves. Thus sophisticated systems of analysis are likely to be required (Phillips, 1984) in order to determine what should be done and how to get the coalition needed to adopt and implement the changes. These situations involve making use of ideas from political science, management science, cognitive psychology, social psychology, strategic management, leadership studies, systems thinking, and so forth. Managers are rarely concerned with theoretical integration. With good reason, they are more interested in what works and what helps them. Acting in practice for these managers - and for us, too, much of the time-provides a testing ground for ideas as well as 'data' on which to reflect concerning the merits of the ideas. Combined approaches may be something that can only be tolerated by truly reflective practitioners, regardless of the persuasiveness of the arguments for greater success of strategic management and/or policy analysis. In the practical world, issues of theory to practice and practice to theory compete directly with the manager as pragmatist keen to reach agreement on what to do, rather than the manager as reconciler of competing theories/rationalities/views.

\section{Can conflicting theories be practical together?}

Mixing methodologies has been acknowledged as problematic but important (Eden, 1990; Mingers and Brocklesby, 1997; Munro and Mingers, 2002). As we have suggested above, the tension between several theories of strategic change and analysis may be more important than scholars have acknowledged. We have acknowledged that this may be of little concern to managers, and yet if expert facilitators cannot reconcile these tensions between theory and practice, then that is a serious problem, at least on the theory side. These tensions probably need more consideration than has been shown by those seeking to understand the process of mixing methods. We anticipate that the underlying theories will probably give clues. While our work together has 
made considerable progress in the articulation and resolution of these tensions, we recognize that our collective work is just scratching the surface of what needs to be done. Said differently —and humorously—we find ourselves in the position of the caricatured economist who saw something important happen in the real world, but still felt compelled to ask, 'But will it work in theory?'

So, what was learned from exploring ways of integrating modes of system thinking into public policy making and strategic management practice?

Notwithstanding the issues raised in the last section, each of the authors believes he or she has gained significantly from the efforts to merge modes of system thinking and public policy making and strategic management practice. However, it is interesting to note that the main learning did not derive from the merging of the core of the approaches, but rather from what originally thought of as the peripheral ways of dealing with leadership and facilitation and of adding separable episodes of analysis to the core approaches. This phenomenon both exemplifies and amplifies the implications covered above when discussing the dilemmas and puzzles of merging policy analysis with strategic planning discussed above. The phenomenon also challenges the notion of what is core and what is peripheral to the process of managing policy and strategy change. In other words, what we initially took to be core may not be; leadership and facilitation are probably core as well.

The key aspects of transfer across members of the group were in enhanced understanding of: the nature of reality, problem structuring, stakeholders, leadership, and facilitation.

\section{On the nature of reality}

Group members now have a deeper appreciation of, and ability to hold in tension, two contrasting views of reality; namely, 'objective' reality and 'socially constructed' reality. Said one member, the social construction of reality is not 'laughable' anymore. Indeed, the group came to see the strategic realities for stakeholders and decision makers more as socially negotiated orders and less as objective realities-with the caveat that the challenge is one of getting the balance right between the two. More broadly, the interplay of and tensions between 'facts' and 'meaning' (or 'interpretation') was more fully embraced.

The other major change is a fuller appreciation within the group of the pervasiveness of feedback relationships, especially in complex policy making and strategy change situations. It is very important to attend to the often-unanticipated feedback effects of what we do or want to do and what will or actually does result.

\section{Problem structuring}

All members of the group are now willing to make use of oval mapping as a fast method for getting a group into a problem and for defining project scope. Members of the group are also willing to use scenarios as a way of defining problems. There is also a more general appreciation of the need to test the robustness of strategies further, including through the use of system dynamics modeling. There is also a deeper appreciation of the role of competencies (both individually and combined) to deliver strategy. Finally, there is a richer appreciation of the need for greater attention both to getting the 'right answer' and to assuring that the agreements are in place to adopt and implement the answer.

\section{Stakeholders}

Group members are now more attentive to the need to take both internal and external stakeholders more seriously. This means being more sensitive to stakeholder-related issues, such as the need to elicit and analyse stakeholder views, and the need to distinguish between and pay close attention to both stakeholder analysis and stakeholder management.

\section{Leadership}

Understanding the nature of leadership and the multiple leadership tasks or functions also was enriched, although there is still a confounding of leadership issues with stakeholder issues (ie with viewing the leader as a stakeholder versus the leader as leader). There is now broad recognition that there are multiple ways of supporting and working with a leader, engaging people, and getting started. Leadership is now seen as both top-down and bottom-up and as extending beyond the leader to include aspects of teams, groups, organizations, networks structures, and processes as ways of 'getting things done' (Huxham and Vangen, 2005).

\section{Facilitation}

Considerable enhancement of our understanding and practice of facilitation occurred. The most profound learning involved appreciating the need to pay attention to both content and process, and to get the balance right. One member shifted his view from believing that strategic change was $90 \%$ process and $10 \%$ content to the view that it is often more like 5050. Other members grew more attentive the importance of attending to and emphasizing political feasibility-meaning the joining of the idea and the coalition.

Members of the group appreciate more fully than ever the continuing need to learn facilitation skills from other skilled facilitators. This appreciation comes in part from recognizing the bounded competences of facilitators (that cannot easily be cured by adding more facilitators). Finally, the group came to value the importance of honest disagreement.

\section{Conclusion}

This paper has described the efforts of six academics working from three different though complementary theoretical foundations and intervention backgrounds (ie ways of working) 
to create methods of policy making and strategy change that are inclusive, analytic, and quick. We have pursued this challenge through developing a conceptual framework for integrating modes of systems thinking into public policy making and strategic management practice. We must conclude by saying that we have only partially succeeded. We do have an approach that works with reasonably large groups and organizations and that we can teach.

The integrated approach emphasizes the importance of: leadership, the management of meaning, the use of VIM, the development of a holistic view of the problematic situation, and facilitation. But a number of dilemmas and puzzles remain. They include figuring out how to address both theoretically and practically the following tensions: getting the 'right policy' versus reaching agreement; strategic management versus strategy or policy analysis; which process steps to follow; the extreme demands on managers or policy-makers and demands on facilitators and analysts; and, finally, figuring out whether conflicting theories can be practical together.

The need for methods that are inclusive, analytic, and quick remains an important theoretical and practical challenge. However, the experiences reported here made considerable progress in other ways.

The need to prosecute a very careful research design was paramount. The researchers each had huge personal investment and emotional as well as cognitive commitment to their own ways of working, even though they were also committed to improving methods. The qualitative research method employed facilitated the exploration of the link between theory and practice in a manner that turned out to be much more successful than envisaged. The combination of the diverse but interrelated methods of designed discussions proved to be a rich source of data. In particular, each scholar changed his or her own approach as a result of: the continuously modified records of discussion using causal mapping, designing and presenting a teaching programme, and designed reflections on the successes and failures of the integrated approach. The triangulation between each of these aspects revealed both logical and epistemological tensions. Similarly, there was success in meeting the challenge of designing a research conversation that could engage the multi-disciplinary backgrounds of the six participants: mathematics and systems modeling, managerial and organizational cognition, social psychology, group behaviour, leadership, public policy analysis, and strategic management.

Although the intention was to converge on a new, more widely encompassing, integrated approach to strategy and policy making, the contribution to the field that actually resulted is possibly of greater use. For both practitioners and theorists, identifying key requisite elements of any new approach while also discovering some of the key dilemmas facing a wide-ranging, integrated approach, seem likely to be an important contribution, and one that invites a continuing line of enquiry among other scholars who are interested in improving organizational strategy making.

\section{References}

Ackermann F and Eden C (1994). Issues in computer and noncomputer supported GDSSs. Int J Decis Supp Syst 12: 381-390.

Ackermann F and Eden C (2001). Contrasting single user and networked group decision support systems for strategy making. Group Decis Negotiat 10: 47-66.

Ackermann F, Eden C and Brown I (2005a). The Practice of Making Strategy. Sage: London.

Ackermann F, Eden C and Williams T (1997). Modeling for litigation: Mixing qualitative and quantitative approaches. Interfaces 27: $48-65$.

Ackermann F, Franco LA, Gallupe B and Parent M (2005b). Group support systems for multi-organizational collaboration: Reflections on process and content. Group Decis Negotiat 14: 307-331.

Andersen DF, Bryson JM, Richardson GP, Ackermann F, Eden C and Finn CB (2006). Integrating modes of systems thinking into strategic planning education and practice: The Thinking Person's Institute approach. J Publ Affairs Educ 12: 265-293.

Andersen DF and Richardson GP (1980). Toward a pedagogy of system dynamics. TIMS Stud Mngt Sci 14: 91-106.

Andersen DF and Richardson GP (1997). Scripts for group model building. Syst Dyn Rev 13: 107-130.

Andersen DF, Richardson GP and Vennix JAM (1997). Group model building: Adding more science to the craft. Syst Dyn Rev 13: 187-201.

Argyris C and Schon DA (1974). Theories in Practice. Jossey Bass: San Francisco.

Argyris C and Schon DA (1978). Organizational Learning: A Theory of Action Perspective. Addison-Wesley: Reading, MA.

Bardach EA (2004). Practical Guide for Policy Analysis, 2nd edn., Congressional Quarterly Press: Washington, DC.

Behn RD and Vaupel JW (1982). Quick Analysis for Busy Decision Makers. Basic Books: New York, NY.

Berger PL and Luckmann T (1966). The Social Construction of Reality. Doubleday: New York.

Blenkin GM and Kelly AV (2001). Action Research for Professional Development. Paul Chapman: London.

Bryson JM (2003). Strategic planning and management. In: Peters BG and Pierre J (eds). Handbook of Public Administration. Sage: London, pp 38-47.

Bryson JM (2004). Strategic Planning for Public and Nonprofit Organizations, 3rd edn., Jossey-Bass: San Francisco.

Bryson JM and Finn CB (1995). Creating the future together: Developing and using shared strategy maps. In: Halachmi A and Bouckaert G (eds). The Enduring Challenges in Public Management. Jossey-Bass: San Francisco, pp 247-280.

Bryson JM, Ackermann F, Eden C and Finn C (1995). Using the 'Oval Mapping Process' to identify strategic issues and formulate effective strategies. In: Bryson JM (ed). Strategic Planning for Public and Nonprofit Organisations. Jossey Bass: San Francisco, pp 257-275.

Bryson JM, Ackermann F, Eden C and Finn C (2004). Visible Thinking: Unlocking Causal Mapping for Practical Business Results. Wiley: Chichester.

Bryson JM, Cunningham GL and Lokkesmoe KJ (2002). What to do when stakeholders matter: The case of problem formulation for the African American Men Project of Hennepin County, Minnesota. Public Admin Rev 62: 568-584.

Camerer CF and Johnson EJ (1991). The process-performance paradox in expert judgment. In: Ericsson KA and Smith J (eds). Towards a General Theory of Expertise: Prospects and Limits. Cambridge University Press: New York. 
Checkland P and Holwell S (1998). Action research: Its nature and validity. Syst Pract 11: 9-21.

Crosby BC and Bryson JM (2005). Leadership for the Common Good, 2nd edn. Jossey-Bass: San Francisco, CA.

Eden C (1990). The unfolding nature of group decision support. In: Eden C and Radford J (eds). Tackling Strategic Problems: The Role of Group Decision Support. Sage: London, pp 48-52.

Eden C and Ackermann F (1998). Making Strategy: The Journey of Strategic Management. Sage: London.

Eden C and Ackermann F (2000). Mapping distinctive competencies: A systemic approach. J Opl Res Soc 51: 12-20.

Eden C and Ackermann F (2001a). Group decision and negotiation in strategy making. Group Decis Negotiat 10: 119-140.

Eden C and Ackermann F (2001b). A mapping framework for strategy making. In: Huff A and Jenkins M (eds). Mapping Strategy. Wiley: London, pp 173-195.

Eden C and Huxham C (1996). Action research for the study of organizations. In: Clegg S, Hardy C and Nord W (eds). Handbook of Organization Studies. Sage: Beverly Hills, pp 526-542.

Eden C, Jones S, Sims D and Smithin T (1981). The intersubjectivity of issues and issues of intersubjectivity. J Mngt Stud 18: 37-47.

Eisenhardt KM (1989). Building theories from case study research. Acad Mngt Rev 14: 532-550.

Finn C (1996). Utilizing stakeholder strategies for positive collaboration. In: Huxham C (ed). Creating Collaborative Advantage. Sage: London, pp 152-164.

Finn, C (1997). Stakeholder analysis. PhD thesis, University of Strathclyde: Glasgow, Scotland.

Forrester J (1969). Urban Dynamics. MIT Press: Cambridge, MA.

Holman P and Devane T (1999). The Change Handbook. BerrettKoehler: San Francisco, CA.

Howick S, Ackermann F and Andersen D (2006). Linking event thinking with structural thinking: Methods to improve client value in projects. Syst Dyn Rev 22: 113-140.

Howick, S, Eden, C, Ackermann, F, Williams, T (2007). Building confidence in models for multiple audiences: The modelling cascade. Eur J Opl Res, (forthcoming).

Huxham C and Cropper S (1994). From many to one-and back: An exploration of some components of facilitation. Omega 22: 1-11.

Huxham C and Vangen S (2005). Managing to Collaborate. Routledge: London.

Janis IL (1972). Victims of Group Think. Houghton Mifflin: Boston.

Kim WC and Mauborgne RA (1995). A procedural justice model of strategic decision making. Org Sci 6: 44-61.

Kolb DA (1984). Experiential Learning. Prentice-Hall: Englewood Cliffs, NJ.

Milling PM (1989). The Design of Strategy Support Systems, Advances in Support Systems Research. I.A.S.: Windsor, Ontario.

Mingers J and Brocklesby J (1997). Multi-methodology: Towards a framework for mixing methodologies. Omega 25: 489-509.

Mitroff II and Featheringham TR (1974). On systemic problem solving and the error of the third kind. Behav Sci 19: 383-393.

Morecroft J (1984). Strategy support models. Strat Mngt J 5: $215-229$.
Munro I and Mingers J (2002). The use of multimethodology in practice-Results of a survey of practioners. J Opl Res Soc 53: 369-378.

Pettigrew A (1977). Strategy formulation as a political process. Int Stud Mngt Org 7: 78-87.

Pettigrew A, Whittington R, Melin L, Sanchez-Runde, Van den Bosch, Ruitgrok and Numagami (2003). Innovative Forms of Organizing. Sage: London.

Phillips LD (1984). A theory of requisite decision models. Acta Psychol 56: 29-48.

Phillips R (2003). Stakeholder Theory and Organizational Ethics. Berrett-Koehler: San Francisco.

Richardson G (1991). Feedback Thought in Social Science and Systems Theory. University of Pennsylvania Press: Philadelphia.

Richardson G and Pugh III AL (1981). Introduction to System Dynamics Modeling. Productivity Press: Boston, MA.

Schweiger DM, Sandberg WR and Rechner PL (1989). Experiential effects of dialectical inquiry, devil's advocacy, and consensus approaches to strategic decision making. Acad Mngt J 32: $745-772$.

Senge P (1992). The Fifth Discipline. Doubleday: New York.

Sterman JD (2000). Business Dynamics: Systems Thinking and Modeling for a Complex World. Irwin McGraw-Hill: Chicago.

Warren KD (2002). Competitive Strategy Dynamics. Wiley: Chichester.

Weimar D and Vining A (2004). Policy Analysis: Concepts and Practice, 4th edn. Prentice-Hall: Englewood Cliffs, NJ.

Wildavsky A (1979). Speaking Truth to Power. Little: Brown, Boston, MA.

Wolstenholme EF and Coyle RG (1983). The development of system dynamics as a methodology for system description and qualitative analysis. J Opl Res Soc 34: 569-581.

Zagonel, AA (2002). Model conceptualization in group model building: A review of the literature exploring the tension between representing reality and negotiating a social order. In: Proceedings of the 20th International Conference of the System Dynamics Society, Palermo, Italy, The System Dynamics Society.

Zagonel, AA (2003). Using group model building to inform welfare reform policy-making in New York State: A critical look. In: Proceedings of the 21st International Conference of the System Dynamics Society, New York City, USA, The System Dynamics Society.

Zagonel, AA (2004). Developing an interpretive dialogue for group model building. In: 22nd International Conference of the System Dynamics Society, Oxford, England, The System Dynamics Society.

Zahn, EKO, Greschner, J (1993). Model-based planning for strategic management: An integrated simulation and learning toolkit. In: International System Dynamics Conference, Cancun, Mexico, System Dynamics Society.

Received June 2007; accepted December 2007 after one revision

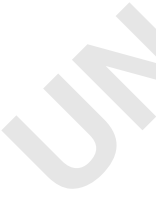

